Provided for non-commercial research and education use. Not for reproduction, distribution or commercial use.

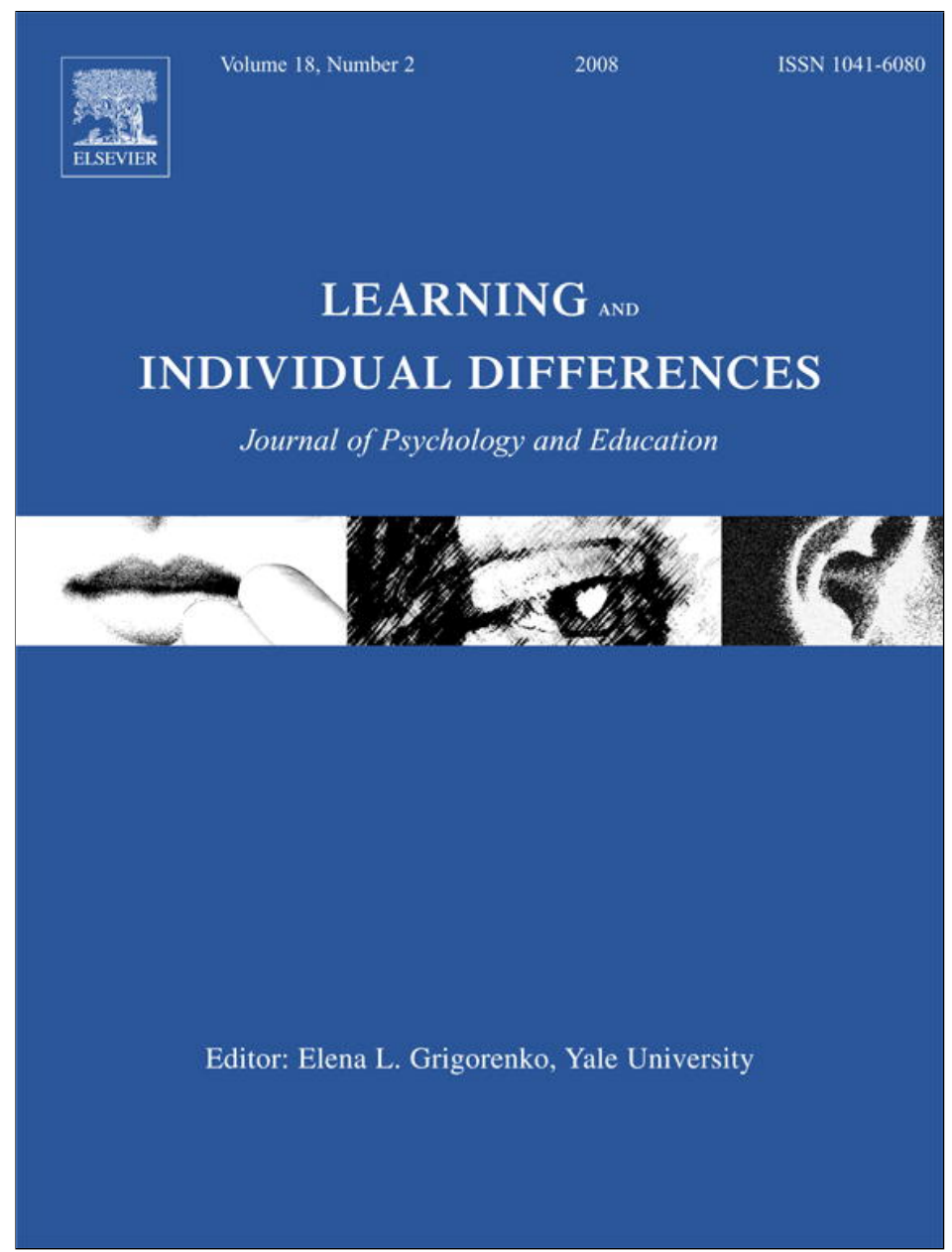

This article appeared in a journal published by Elsevier. The attached copy is furnished to the author for internal non-commercial research and education use, including for instruction at the authors institution and sharing with colleagues.

Other uses, including reproduction and distribution, or selling or licensing copies, or posting to personal, institutional or third party websites are prohibited.

In most cases authors are permitted to post their version of the article (e.g. in Word or Tex form) to their personal website or institutional repository. Authors requiring further information regarding Elsevier's archiving and manuscript policies are encouraged to visit:

http://www.elsevier.com/copyright 


\title{
Attentional and executive function behaviours in children with poor working memory
}

\author{
Susan E. Gathercole ${ }^{\mathrm{a}, *}$, Tracy P. Alloway ${ }^{\mathrm{b}}$, Hannah J. Kirkwood ${ }^{\mathrm{b}}$, Julian G. Elliott ${ }^{\mathrm{b}}$, \\ Joni Holmes ${ }^{\mathrm{a}}$, Kerry A. Hilton ${ }^{\mathrm{b}}$ \\ ${ }^{\mathrm{a}}$ University of York, United Kingdom \\ ${ }^{\mathrm{b}}$ University of Durham, United Kingdom
}

Received 31 January 2007; received in revised form 30 August 2007; accepted 7 October 2007

\begin{abstract}
The purpose of this study was to explore the profiles of classroom behaviour relating to attention and executive functions in children with very poor working memory, and to test the hypothesis that inattentive behaviour and working memory problems co-occur. Teachers rated problem behaviours of 52 children with low working memory scores aged 5/6 and 9/10 years on teacher rating measures of attention and executive function behaviours. The majority of children with low working memory scores obtained atypically high ratings of cognitive problems/ inattentive symptoms, and were judged to have short attention spans, high levels of distractibility, problems in monitoring the quality of their work, and difficulties in generating new solutions to problems. These results extend previous findings that working memory problems and inattentive behaviour co-occur to a non-clinical sample. It is suggested that reduced working memory capacity may play a causal role in the problem behaviours of these children.
\end{abstract}

(C) 2007 Elsevier Inc. All rights reserved.

Keywords: Working memory; Attention; Executive function; Reading; Mathematics; Problem behaviors

One of the key factors influencing a child's ability to learn is working memory - the capacity to hold in mind and manipulate information for brief periods of time. Children's working memory skills are closely associated with their academic progress in both reading (Swanson, Ashbaker, \& Lee, 1996; Gathercole Pickering, Knight \& Stegmann, 2004) and mathematics (Swanson, 2006; Geary, Hoard, Byrd, De Soto, \& Craven, 2004), with the majority of children with specific learning difficulties in these areas having poor working memory skills (Gathercole, Alloway, Willis, \& Adams, 2006; Pickering $\&$ Gathercole, 2004). The present study is the first of its kind to explore the profiles of classroom behaviour of children with very poor working memory, with the aim of developing understanding of the learning difficulties experienced by most of

\footnotetext{
* Corresponding author. Department of Psychology, University of York, Heslington, York, YO10 5DD, England, United Kingdom. Tel.: +1904 432879. E-mail address: s.gathercole@psychology.york.ac.uk (S.E. Gathercole).
}

these children. The study is primarily descriptive in nature, with the purpose of documenting the extent to which the children exhibited problem behaviours associated with disorders of attention as well as a range of other executive functions.

Working memory is one of several executive functions that is typically impaired in children with ADHD (Barkley, 1997; Castellanos, Sonuga-Barke, Millam, \& Tannock, 2006; Martinussen, Hayden, Hogg-Johnson, \& Tannock, 2005; Willcutt, Doyle, Nigg, Faraone, \& Pennington, 2005). Martinussen and Tannock (2006) found that children with a clinical diagnosis of ADHD but no co-morbid reading or language difficulties scored poorly both on complex memory span tasks involving the storage and processing of either verbal and or visuo-spatial material, and on storage-only measures of visuo-spatial but not of verbal material. The decrements in complex span performance indicate that these children have poor functioning of the central executive component of the Baddeley and Hitch (1974) working memory model (see also, Baddeley, 1986, 2000). The central executive is domain-general in nature, and is associated 
with the allocation of limited-capacity attentional resources to support the processing element of complex span tasks (Alloway, Gathercole, \& Pickering, 2006; Bayliss, Jarrold, Gunn, and Baddeley, 2003; Kane, Hambrick, Tuholski, Wilhelm, Payne, \& Engle, 2004). The accompanying visuo-spatial storage deficit may either reflect problems with the relevant storage component of working memory (the visuo-spatial sketchpad), or it too may be a consequence of poor functioning of the central executive (Alloway et al., 2006; Thompson et al., 2006).

Martinussen and Tannock (2006) also found that working memory performance was associated with some of the problem behaviours identified by teachers and parents for this sample. Complex memory scores were significantly associated with ratings of clinical symptoms of inattention, but not with ratings of the hyperactive/ impulsive symptoms that are also often present in ADHD. Corresponding links with inattentivity were not found for scores on the storage-only tasks in either the verbal or visuospatial domain. Further evidence that inattentive behaviour and poor working memory are related was provided in a computerised training study of working memory in children with ADHD (Klingberg et al., 2005). Following training, the children in this study showed significant improvements both in memory performance and in parent ratings of inattentive symptoms.

One hypothesis tested in the present study was that inattentive behaviour is also characteristic of children with poor working memory skills attending mean stream schools who do not have a clinical diagnosis of ADHD. The children were selected on the basis of low scores on measures of verbal working memory from the Automated Working Memory Assessment (Alloway, 2007). Attentional behaviours for these children were rated by teachers using the Conners' Teaching Rating Scale-Revised (CTRS-R, 2001), a measure that yields subscale scores relating to oppositional, inattentive, and hyperactive-impulsive behaviours, in addition to an ADHD index score associated with likelihood of an ADHD diagnosis. The CTRS is widely used as a means of assessing the different dimensions of behaviours associated with ADHD and other developmental disorders (e.g., Martinussen \& Tannock, 2006; Mehta, Goodyer, \& Sahakian, 2004; Tripp, Schaughency, \& Clarke, 2006), and has good discriminant validity for children identified according to the DSM-IV criteria for ADHD (Conners, 2001).

Preliminary evidence that working memory and attentional deficits co-occur in non-clinical samples was provided in a recent study in which we observed the classroom behaviour of children aged 5 and 6 years who had scored very poorly on complex memory span tests of working memory at school entry 1 year earlier (Gathercole, Lamont, \& Alloway, 2006). Compared with classmates with typical working memory skills, the low memory children frequently forgot the content of instructions relating both to classroom management and to specific tasks (see also, Engle, Carullo, \& Collins, 1991), struggled with activities that required both the storage and processing of material, and often lost their place in complex tasks. The most common consequence of these failures was that the children abandoned the activity without completing it. Importantly, the teachers described the children as being inattentive. Aronen, Vuontela, Steenari, Salmi, \& Carlson (2005) also reported in a study of an unselected sample of children that working memory scores were associated with teacher ratings of attentional and behavioural difficulties.

Ratings of problem behaviours relating to a range of executive functions were also obtained for the children with low working memory who participated in this study. Executive functions are higher-level processes involved in the top-down control of cognitive processes that facilitate goal-directed behaviour, and include planning, inhibition, task switching, and attention, as well as working memory (Miyake, Friedman, Emerson, Witzki, Howerter, \& Wager 2000; Stuss \& Alexander, 2005). Problems of inhibition, particularly related to the control of pre-potent motor responses, characterise the majority of children with ADHD (Nigg, 2001; Pennington \& Ozonoff, 1996; Willcutt et al., 2005), and are believed by some to represent the core deficit of this disorder (Barkley, 1997). In order to gain a preliminary assessment of the extent to which the poor working memory function of the children selected to participate in this study extends to other executive functions, teachers also completed the Behavior Rating Inventory of Executive Function for each child (BRIEF, Gioia, Isquith, Guy, \& Kenworthy, 2000). This is a behaviour checklist that yields subscale scores relating to the following aspects of executive function: inhibition, shifting, emotional control, initiation, planning/ organization, organization of material, monitoring, and working memory. The BRIEF is widely used both for the purposes of clinical assessment and of research on a variety of developmental cognitive disorders (Anderson, Anderson, Northam, Jacobs, \& Mikiewicz, 2002; Mahone, Zabel, Levey, Verda, \& Kinsman, 2003; Slick, Lautzenhiser, Sherman, \& Eyri, 2006), and has a high predictive validity for discriminating children with clinical diagnoses of subtypes of ADHD (Gioia et al., 2000).

The participants with low working memory in this study were drawn from two age groups $-5 / 6$ years and $9 / 10$ years - in order to test whether there were any age-related differences in atypical patterns of problem behaviours associated with attention or executive functions. Other measures included in the study were receptive vocabulary, IQ, and attainments in reading and mathematics.

\section{Method}

\subsection{Participants and design}

In the screening phase of the study (time 1), two working memory measures were administered to 852 children aged 4 and 5 years during their last term of the first year of full-time education and 957 children aged 8 and 9 years in the final term of their fifth year of school. The children attended 43 local education authority schools in County Durham, England that were selected to reflect the national demographic profile of children receiving free school meals and of performance on national Key Stage 2 assessments in English, maths and science at 11 years.

All children completed two verbal complex span tests of the Automated Working Memory Assessment (AWMA, Alloway, 2007) in an individual testing session located in a quiet room in school. The listening recall test involves the child listening to 
spoken sentences, judging whether each sentence is true and false, and attempting to recall the final words of each sentence presented on a trial, in their original sequence. In the backward digit recall test, the child attempts to recall a sequence of auditorily presented digit names in their reverse serial order. In both cases, standard scores (population mean $=100, \mathrm{SD}=15$ ) were computed and were averaged to form a composite score. For children aged 4.5 to 11.5 years, test-retest reliability coefficients are .81 for listening recall and .64 for backward digit recall.

Data from a subgroup of children from the screening sample with very low composite scores (at or below the 8th centile of the screening sample) formed the basis for the present report. The younger group consisted of 18 boys and 11 girls, with a mean age of 67.83 months $(\mathrm{SD}=3.72$, range $=63$ to 75$)$. The older group consisted of 16 boys and 7 girls, with a mean age of 114.91 months $(\mathrm{SD}=3.70$, range $=109$ to 123$)$. Of the 52 children, 17 (33\%) were identified by their schools as having difficulties relating to learning. These ranged in severity from a record of concern $(n=2)$ to statements of special educational needs that require additional resources in school $(n=40)$. The areas of difficulty included learning difficulties in specific areas such as reading and language, as well as more generalized difficulties. Two children were receiving speech and language therapy. In two further cases, the areas of concern included behaviour as well as learning.

\subsection{Procedure}

\subsubsection{Working memory}

The remaining 10 tests of the AWMA (Alloway, 2007) were administered at time 2 . These consisted of three verbal shortterm memory measures (digit recall, word recall, and nonword recall, three visuo-spatial short-term memory measures (dot matrix, mazes memory, and block recall), three visuo-spatial complex memory tests (odd-one-out, $\mathrm{Mr} \mathrm{X}$, and spatial span) and one further test of verbal complex memory (counting recall). Standard scores were calculated for each individual test, and composite scores based on the three tests measuring each of the four aspects of working memory. Four further tests were administered at time 3 , in order to assess the stability of working memory skills over the school year: nonword recall, dot matrix, spatial span, and backward digit recall. Test-retest reliability coefficients for children aged 4.5 to 11.5 years for each measure are: digit recall (.84), word recall (.76), nonword recall (.64), dot matrix (.83), mazes memory (.81), block recall (.83), odd-oneout (.81), Mr X (.77), spatial span (.82), counting recall (.81).

\subsubsection{Ability tests}

The Wechsler Objective Reading Dimensions (WORD, Wechsler, 1993) provides separate tests of basic reading, reading comprehension, and spelling. The Wechsler Objective Numerical Dimensions (WOND, Wechsler, 1996) assesses mathematical reasoning and number operations. General cognitive abilities were tested using the Wechsler Abbreviated Scale of Intelligence (WASI, Wechsler, 1999). This consists of four subtests: the vocabulary and similarities form the verbal scale, and block design and matrix reasoning form the performance scale. IQ scores are calculated for each scale. The British Picture Vocabulary Scale II-Short Form (BPVS, Dunn, Dunn, Whetton, \& Pintillie, 1997) provides a measure of receptive vocabulary. At time 3, the children were re-tested on the WORD, WOND, and BPVS.

\subsubsection{Teacher rating scales}

Teachers completed two rating scales for the participating children between three and six months after time 2 . The Conners' Teacher Rating Scale-Revised, Short Form (CTRS$R, 2001)$ is designed to identify attentional failures and ADHD on the basis of classroom behaviours. In this test, teachers are asked to rate the extent to which the child has had problem behaviours in school over the past month that are described in 28 brief statements on the form. The response choices for each behaviour are: not true at all, just a little true, pretty much true, and very much true. Responses are scored as sums of values on four subscales-oppositional (e.g., spiteful or vindictive), cognitive problems/ inattention (e.g., forgets things s/he has already learned), hyperactivity (e.g., is always "on the go" or acts as if driven by a motor), and ADHD index (e.g., restless, always up and on the go). The ADHD Index is based on the best set of items for identifying children at risk of a diagnosis of ADHD. $T$-scores (with a population mean of 50 and SD of 10) are calculated for each of the four subscales. Test-retest reliability coefficients for subscale scores reported for a sample of 50 children with a mean age of 11 years were as follows: oppositional (.62), cognitive problems/ inattention (.73), hyperactivity (.85), and ADHD Index (.72).

The Behavior Rating Inventory of Executive Function (BRIEF, Gioia et al., 2000) assesses problem behaviours associated with executive function. The form consists of 86 brief descriptions of behaviour problems, the frequency of which teachers are asked to rate as occurring either never, sometimes, or often. Responses are aggregated to form eight subscales. The inhibit scale measures the ability to control impulses, and to stop own behaviour at the proper time. The shift scale assesses the ability to move freely from one situation, activity, or aspect of a problem to another as the situation demands; it also taps behaviours relating to transition, and to the ability to solve problems in a flexible manner. The emotional control scale relates to the ability to modulate emotional responses appropriately. The initiate scale measures the ability to begin a task or activity, and to generate ideas independently. The working memory scale assesses the ability to hold information in mind for the purpose of completing an activity. The plan/organize scale assesses abilities to anticipate future events, set goals, develop appropriate steps ahead of time, carry out tasks in a systematic manner, and to understand and communicate main idea. The organization of materials scale relates to abilities to maintain relevant parts of the environment in an orderly manner. The monitor scale relates to abilities to check work, assess performance, and to keep track of own and others' efforts. Examples of test items from each subscale are shown in the Appendix A. T-scores are calculated for each measure. Test-retest correlations for individual subscale score 
Table 1

Descriptive statistics on the working memory measures for the AWMA ${ }^{\mathrm{a}}$, by age group

\begin{tabular}{|c|c|c|c|c|c|c|c|c|c|}
\hline \multirow[b]{2}{*}{ Measure } & \multirow{2}{*}{$\begin{array}{l}\begin{array}{l}\text { Age } \\
\text { group: }\end{array} \\
\text { Time }\end{array}$} & \multicolumn{4}{|c|}{$5 / 6$ years } & \multicolumn{4}{|c|}{$9 / 10$ years } \\
\hline & & Mean & SD & Min & Max & Mean & SD & Min & Max \\
\hline \multicolumn{10}{|l|}{ Verbal STM } \\
\hline $\begin{array}{l}\text { Digit } \\
\text { recall }\end{array}$ & 2 & 76.59 & 13.41 & 63 & 106 & 78.74 & 10.23 & 70 & 104 \\
\hline $\begin{array}{l}\text { Word } \\
\text { recall }\end{array}$ & 2 & 85.52 & 17.32 & 58 & 126 & 83.13 & 11.91 & 58 & 102 \\
\hline $\begin{array}{l}\text { Nonword } \\
\text { recall }\end{array}$ & 2 & 83.76 & 13.21 & 55 & 102 & 85.61 & 10.90 & 68 & 103 \\
\hline Composite & 2 & 77.83 & 14.94 & 55 & 107 & 79.48 & 9.48 & 63 & 99 \\
\hline $\begin{array}{l}\text { Nonword } \\
\text { recall }\end{array}$ & 3 & 88.69 & 10.73 & 71 & 155 & 80.91 & 10.87 & 63 & 101 \\
\hline \multicolumn{10}{|l|}{ Verbal WM } \\
\hline $\begin{array}{l}\text { Listening } \\
\text { recall }\end{array}$ & 1 & 74.03 & 3.33 & 67 & 77 & 76.43 & 4.33 & 71 & 81 \\
\hline $\begin{array}{l}\text { Backward } \\
\text { digit recall }\end{array}$ & 1 & 73.52 & 6.81 & 61 & 78 & 77.78 & 2.13 & 74 & 81 \\
\hline $\begin{array}{l}\text { Counting } \\
\text { recall }\end{array}$ & 2 & 74.55 & 9.89 & 56 & 94 & 79.78 & 10.21 & 62 & 104 \\
\hline Composite & 1,2 & 67.45 & 4.75 & 60 & 76 & 73.26 & 4.96 & 63 & 82 \\
\hline $\begin{array}{l}\text { Backward } \\
\text { digit recall }\end{array}$ & 3 & 67.93 & 11.64 & 58 & 94 & 79.57 & 6.71 & 69 & 93 \\
\hline \multicolumn{10}{|c|}{ Visuo-spatial WM } \\
\hline Dot matrix & 2 & 82.76 & 14.50 & 62 & 114 & 77.43 & 15.14 & 58 & 108 \\
\hline $\begin{array}{l}\text { Mazes } \\
\text { memory }\end{array}$ & 2 & 86.03 & 13.30 & 74 & 124 & 88.48 & 16.74 & 58 & 117 \\
\hline $\begin{array}{l}\text { Block } \\
\text { recall }\end{array}$ & 2 & 83.79 & 11.57 & 64 & 115 & 81.35 & 14.95 & 59 & 108 \\
\hline Composite & 2 & 80.34 & 12.14 & 66 & 122 & 78.70 & 14.19 & 57 & 107 \\
\hline $\begin{array}{l}\text { Dot } \\
\text { matrix } t\end{array}$ & 3 & 80.79 & 14.26 & 58 & 118 & 80.7 & 17.14 & 58 & 108 \\
\hline \multicolumn{10}{|c|}{ Visuo-spatial WM } \\
\hline $\begin{array}{l}\text { Odd one } \\
\text { out }\end{array}$ & 2 & 81.10 & 10.19 & 65 & 108 & 78.39 & 10.11 & 62 & 99 \\
\hline Mr X & 2 & 86.86 & 13.79 & 71 & 116 & 84.26 & 10.59 & 64 & 101 \\
\hline $\begin{array}{l}\text { Spatial } \\
\text { span }\end{array}$ & 2 & 82.03 & 14.44 & 63 & 118 & 79.17 & 15.33 & 57 & 103 \\
\hline Composite & 2 & 79.00 & 13.68 & 58 & 117 & 77.00 & 10.87 & 61 & 98 \\
\hline $\begin{array}{l}\text { Spatial } \\
\text { span }\end{array}$ & 3 & 77.79 & 13.4 & 59 & 107 & 82.13 & 15.66 & 60 & 106 \\
\hline
\end{tabular}

a Automated Working Memory Assessment.

reported for a sample of 41 children were: inhibit (.91), shift (.83), emotional control (.92), initiate (.87), working memory (.87), plan/organize (.88), organization of materials (.83), and monitor (.87).

\section{Results}

\subsection{Working memory}

Descriptive statistics for the two groups on working memory measures are shown in Table 1 . The very low scores on the two verbal complex span measures on which they were selected were also reflected in the further verbal complex memory measure administered at time 2, counting recall, and in the backward digit recall test re-administered at time 3. Poor verbal working memory performance therefore persisted across sub- tests and was stable across a 12-month period. Both groups also performed poorly on the verbal STM, visuo-spatial STM, and visuo-spatial WM subtests administered at time 2, with average composite scores at or below 80 in each case. No significant sex differences were found on any memory measures, in either age group ( $p>.10$ in all cases).

\subsection{Ability measures}

Descriptive statistics for the two low working memory groups on the reading, mathematics, vocabulary and IQ measures are provided in Table 2. No significant sex differences were found on any measure ( $p>.10$ in all cases). Note that due to minimum ages of 6 on several of these measures, standard scores could only be computed for 7 of the younger group at time 2 and for 22 at time 3 (at which time one child was not yet 6 years). Although there is no discrete point at which typical and atypical performance can be unequivocally distinguished, for the present purposes scores at or more than 1 SD below the population mean (below 86) are taken as indicative of a deficit (Gathercole et al., 2006). The following numbers (proportions) of children met this deficit criterion: on the composite WORD reading measure at time $2,4(.57)$ of the young group and 16 (.70) of the older group; on the WORD measure at time 3,14 (.64) of the young group and 16 (.70) of the older group; on the WOND maths composite measure at time 2, $5(.71)$ of the

Table 2

Descriptive statistics on attainment measures, by age group; standard scores except where stated otherwise

\begin{tabular}{|c|c|c|c|c|c|c|c|}
\hline & \multirow{2}{*}{$\frac{\text { Age group: }}{\text { Time }}$} & \multicolumn{3}{|c|}{$5 / 6$ years } & \multicolumn{3}{|c|}{$9 / 10$ years } \\
\hline & & $N$ & Mean & SD & $N$ & Mean & SD \\
\hline \multicolumn{8}{|l|}{ Reading $\left(\mathrm{WORD}^{\mathrm{a}}\right.$ ) } \\
\hline \multirow[t]{2}{*}{ Reading } & 2 & 7 & 89.43 & 6.24 & 23 & 83.13 & 15.91 \\
\hline & 3 & 22 & 89.09 & 7.33 & 23 & 83.52 & 13.33 \\
\hline Reading & 2 & 7 & 85.43 & 9.62 & 23 & 80.70 & 11.48 \\
\hline comprehension & 3 & 22 & 90.55 & 12.77 & 23 & 83.39 & 12.26 \\
\hline \multirow[t]{2}{*}{ Spelling } & 2 & 7 & 86.29 & 5.25 & 23 & 77.39 & 13.88 \\
\hline & 3 & 22 & 84.41 & 6.99 & 23 & 77.70 & 13.25 \\
\hline \multirow[t]{2}{*}{ Composite } & 2 & 7 & 84.29 & 7.09 & 23 & 76.17 & 15.11 \\
\hline & 3 & 22 & 85.36 & 10.13 & 23 & 77.61 & 14.78 \\
\hline \multicolumn{8}{|l|}{ Mathematics $\left(\mathrm{WOND}^{\mathrm{b}}\right.$ ) } \\
\hline Mathematical & 2 & 7 & 88.29 & 5.96 & 23 & 79.91 & 9.86 \\
\hline reasoning & 3 & 22 & 87.68 & 9.28 & 23 & 81.70 & 9.72 \\
\hline \multirow[t]{2}{*}{ Number operations } & 2 & 7 & 86.71 & 9.32 & 23 & 73.00 & 9.76 \\
\hline & 3 & 22 & 87.82 & 9.57 & 23 & 76.61 & 10.08 \\
\hline \multirow[t]{2}{*}{ Composite } & 2 & 7 & 86.29 & 7.61 & 23 & 72.52 & 9.37 \\
\hline & 3 & 22 & 85.68 & 9.14 & 23 & 75.30 & 10.53 \\
\hline \multirow{2}{*}{$\begin{array}{l}\text { Vocabulary } \\
\left(\text { BPVS }^{\mathrm{c}}\right)\end{array}$} & 2 & 29 & 88.17 & 7.49 & 23 & 85.96 & 10.89 \\
\hline & 3 & 29 & 88.14 & 8.00 & 23 & 88.39 & 11.48 \\
\hline \multicolumn{8}{|c|}{ General ability (WASI ${ }^{\mathrm{d}}$ ) } \\
\hline Verbal score $\mathrm{e}^{\mathrm{e}}$ & 2 & 7 & 5.43 & 2.22 & 23 & 3.91 & 2.15 \\
\hline Performance score ${ }^{\mathrm{e}}$ & 2 & 7 & 7.57 & 1.81 & 23 & 6.70 & 1.18 \\
\hline
\end{tabular}

${ }^{\text {a }}$ Wechsler Oral Reading Dimensions.

${ }^{\mathrm{b}}$ Wechsler Oral Number Dimensions.

${ }^{c}$ British Picture Vocabulary Scales.

${ }^{\mathrm{d}}$ Wechsler Abbreviated Scales of Intelligence.

e Scaled scores: population mean $=10, \mathrm{SD}=3$. 
Table 3

Descriptive statistics for the subscale scores on the teacher behaviour rating scales, by age group

\begin{tabular}{|c|c|c|c|c|c|c|c|c|c|c|c|c|c|}
\hline \multirow[b]{2}{*}{ Measure } & \multirow[t]{2}{*}{ Group: } & \multicolumn{4}{|c|}{$\begin{array}{l}\text { Low working memory: } \\
5 / 6 \text { years }\end{array}$} & \multicolumn{4}{|c|}{$\begin{array}{l}\text { Low working memory: } \\
\text { 9/ } 10 \text { years }\end{array}$} & \multicolumn{4}{|c|}{$\begin{array}{l}\text { Typical working memory: } \\
8-11 \text { years }\end{array}$} \\
\hline & & Mean & SD & Min & Max & Mean & SD & Min & Max & Mean & $\mathrm{SD}$ & Min & Max \\
\hline \multicolumn{14}{|l|}{$C T R S^{\mathrm{a}}$} \\
\hline Oppositional & & 62.48 & 18.96 & 44 & 90 & 56.43 & 12.00 & 45 & 87 & 49.95 & 9.75 & 45 & 83 \\
\hline Cognitive problems/ inattention & & 72.45 & 17.37 & 42 & 90 & 69.13 & 9.59 & 54 & 89 & 45.40 & 4.59 & 42 & 56 \\
\hline Hyperactivity & & 60.31 & 15.98 & 43 & 90 & 53.52 & 11.60 & 43 & 81 & 45.90 & 4.00 & 43 & 58 \\
\hline ADHD Index & & 61.62 & 16.37 & 42 & 90 & 60.09 & 12.06 & 44 & 89 & 46.40 & 6.60 & 41 & 69 \\
\hline \multicolumn{14}{|l|}{$B R I E F^{\mathrm{b}}$} \\
\hline Inhibit & & 64.52 & 17.16 & 42 & 103 & 66.35 & 18.71 & 46 & 108 & 46.70 & 6.10 & 42 & 69 \\
\hline Shift & & 66.83 & 10.40 & 48 & 86 & 62.74 & 13.01 & 47 & 87 & 49.95 & 6.22 & 43 & 69 \\
\hline Emotional control & & 73.69 & 22.63 & 49 & 120 & 63.52 & 16.39 & 45 & 91 & 47.00 & 9.14 & 43 & 72 \\
\hline Initiate & & 71.10 & 8.54 & 55 & 84 & 73.74 & 7.04 & 54 & 81 & 48.45 & 7.72 & 41 & 69 \\
\hline Working memory & & 72.45 & 7.13 & 57 & 86 & 76.13 & 9.35 & 55 & 92 & 48.45 & 7.20 & 38 & 63 \\
\hline Plan/ organize & & 64.76 & 9.24 & 48 & 87 & 75.30 & 9.78 & 55 & 89 & 47.80 & 8.36 & 40 & 67 \\
\hline Org. of materials & & 59.79 & 9.80 & 47 & 81 & 67.04 & 19.23 & 44 & 117 & 47.70 & 6.51 & 42 & 63 \\
\hline Monitor & & 70.97 & 13.83 & 48 & 101 & 69.74 & 8.25 & 50 & 81 & 49.85 & 12.89 & 41 & 95 \\
\hline
\end{tabular}

a Conners Teacher Ratings Scale- Short Form.

b Behavior Rating Inventory of Executive Function.

young group and $22(.96)$ of the older group; on the WOND measure at time $3,10(.45)$ of the young group and 21 (.91) of the older group. Thus, a substantial proportion of the children in both age groups were performing below expected levels on both the reading and maths measures, with deficits occurring for the greater majority of children in the older group in both areas, and to the greatest extent in maths. Although vocabulary scores were also low for each group, they did not show the increased deficit in the older group that was evident in the mathematics and reading measures. IQ scores were low, with a greater decrement in verbal than performance IQ.

\subsection{Behaviour ratings}

Table 3 provides descriptive statistics for the two low working memory groups on the two teacher rating measures. This table also includes data from a group of 20 children aged 8 to 11 years (11 boys, 9 girls) with a mean age 9 of years 11 months, $\mathrm{SD}=11.31$ months) who were selected from schools in the same region from the main groups on the basis of verbal working memory scores on the AWMA in excess of 89 . The mean verbal working memory score for this group was $104.85(\mathrm{SD}=9.04)$, and the mean visuo-spatial working memory score was 105.70 (SD= 21.74). This group was included for the purposes comparing the behaviour rating profiles of the two low working memory group, and is labelled the typical working memory group.

Consider first the CTRS-R measure of attentional behaviours, on which elevated scores indicate higher ratings of the frequency of problem behaviours. The mean scores of the typical working memory group were just below 50 on each subscale, corresponding to the expected levels for the population. In contrast in both working memory groups, the mean scores were considerably higher for the cognitive problems/ inattention subscale than for the three other subscales. According to the interpretive guidelines for the test (Gioia et al., 2000), $T$-scores of 55 or below do not represent a cause for concern, scores in the range 56-60 are slightly atypical and should raise concern, scores of 61-65 are mildly atypical and represent a possible significant problem, scores of 66-70 are moderately atypical and represent a significant problem, and scores 70 and greater are markedly atypical. The proportions of children in each of the three groups obtaining scores in each band are shown in Table 4. Whereas all or most of the children in the typical working memory group obtained scores below 61 on each subscale, the majority of the low working memory children obtained scores in the atypical range on the cognitive problems/ inattention subscale ( $79 \%$ for the young group, $70 \%$ for the older group). In contrast, only $30 \%$ of the children in the older group obtained atypically elevated scores on the remaining three subscales. In the younger group, atypically high scores were obtained by $66 \%$ of the children on the ADHD

Table 4

Proportions of children obtaining CTRS-R T-scores in each band as a function of working memory group, age and subscale

\begin{tabular}{|c|c|c|c|c|c|c|}
\hline $\begin{array}{l}\text { Working } \\
\text { memory group }\end{array}$ & Age & Subscale & $<61$ & $61-65$ & $66-70$ & $71+$ \\
\hline \multirow[t]{8}{*}{ Low } & \multirow[t]{4}{*}{$5 / 6$} & Oppositional & .55 & .07 & .07 & .31 \\
\hline & & $\begin{array}{l}\text { Cognitive problems/ } \\
\text { inattention }\end{array}$ & .21 & .17 & .17 & .45 \\
\hline & & Hyperactivity & .59 & .07 & .10 & .24 \\
\hline & & ADHD Index & .34 & .28 & .10 & .28 \\
\hline & \multirow[t]{4}{*}{$9 / 10$} & Oppositional & .70 & .13 & .00 & .17 \\
\hline & & $\begin{array}{l}\text { Cognitive problems/ } \\
\text { inattention }\end{array}$ & .30 & .09 & .04 & .57 \\
\hline & & Hyperactivity & .70 & .09 & .00 & .22 \\
\hline & & ADHD Index & .70 & .13 & .04 & .13 \\
\hline \multirow[t]{4}{*}{ Typical } & \multirow[t]{4}{*}{$8-11$} & Oppositional & .90 & .00 & .05 & .05 \\
\hline & & $\begin{array}{l}\text { Cognitive problems/ } \\
\text { inattention }\end{array}$ & 1.00 & .00 & .00 & .00 \\
\hline & & Hyperactivity & 1.00 & .00 & .00 & .00 \\
\hline & & ADHD Index & .95 & .00 & .05 & .00 \\
\hline
\end{tabular}


Index, $45 \%$ on the oppositional subscale, and $41 \%$ on the hyperactivity subscale. No significant sex differences in the scores were present in any group ( $p>.10$, in all cases).

In order to identify the specific problem behaviours characterizing this sample on the CTRS-R, an items analysis was conducted on the data for 47 children for whom the test sheets were available at the time of re-analysis. For each of the following behaviours, over half of the children obtained high ratings of either 2 (pretty much true) or 3 (very much true) on the following items: forgets other things s/he has learned (77\%); poor in spelling (72\%); poor in arithmetic (70\%); not reading up to $\operatorname{par}(70 \%)$, inattentive, easily distracted (64\%), distractibility or attention span a problem $(60 \%)$, short attention span $(60 \%)$, lacks interest in schoolwork (51\%), and only pays attention to things $\mathrm{s} /$ he is really interested in $(51 \%)$. These behaviours constituted all five of the problem behaviours contributing to the cognitive problems/ inattention subscale, and 4 of the 12 problem behaviours contributing to the ADHD index.

The elevated scores of a sizeable proportion of the children on the ADHD index subscale were largely due to high ratings on four of the 12 problem behaviours that form this scale, all of which relate to inattention and short attention span: inattentive/ easily distracted, short attention span, distractibility or attention span a problem, and only pays attention to things s/he is really interested in. The hyperactive/ impulsive symptoms that are typically present in children with a diagnosis of ADHD were not greatly elevated in this sample.

Descriptive statistics of the two low working memory groups and the comparison group of children with typical working memory on the subscales from the BRIEF measure of executive function are shown in Table 3. The mean scores of the typical working memory group were close to 50 in each case, corresponding to the expected values for the population as a whole. In the older low working memory group, highest (i.e. more problematic) subscale scores were obtained on the initiate, working memory and plan/ organize scales, with mean scores in excess of 70 in both cases. The remaining basic scale scores fell in the 60 to 70 range. The younger group obtained mean scores in excess of 70 on the emotional control, working memory and initiate subscales, with lower levels of problem behaviours aszsociated with the organisation of materials and shifting. Scores of 65 and above on the BRIEF are considered to be of potential clinical significance (Gioia et al., 2000). The proportions of children with scores in this elevated range were calculated for each subscale (young low working memory, older low working memory, typical working memory): inhibit (.48, $.44, .05)$, shift $(.45, .48, .05)$, emotional control $(.59, .43, .15)$, initiate $(.62,43, .05)$, working memory $(.86, .91, .00)$, planning/ organization $(.69, .65, .05)$, organization of material $(.28, .30$, $.00)$, monitor $(.72,70, .05)$. The highest levels of clinically significant problem behaviours of the two low working memory groups were therefore found on the working memory subscale; approximately two-thirds of the children also obtained elevated scores on the monitoring and planning/ organization subscales, and about half of the group had elevated scores on the inhibition, shifting, emotional control, and initiate scales. High scores on the latter two subscales were more frequent for the younger than the older group although for the remaining subscales, the incidence of clinically significant behaviours was highly consistent across the two age groups.

In order to identify the specific problem behaviours relating to executive function that were most commonly found in this sample, an items analysis was conducted for 50 of the children on whom test forms were available at the time of re-scoring. The proportion of children obtaining the highest frequency rating (in which a behaviour was judged to be often true of the child, scored as 3) was also calculated for each item. For each of the following behaviours, at least half of the children obtained a score of 3: does not check work for mistakes (.74), has trouble thinking of a different way to solve a problem when stuck (.72), written work is poorly organised (.72), makes careless errors (.70), needs help from an adult to stay on task (.62), has short attention span (.60), has problems coming up with different ways of solving a problem (.60), is easily distracted by noises, activity, sights, etc (.58), does not show creativity in solving a problem (.56), work is sloppy (.52), and has trouble concentrating on chores, schoolwork, etc (.50). Four problem behaviours are associated with the working memory subscale: poor attention span, high distractibility, and the need for adult support. Three behaviours are from the monitoring subscale: these relate to failures to checking work and sloppiness. A further three behaviours were from the inhibition subscale, and concerned lack of creativity in reaching solutions in complex tasks. A single problem associated with the planning/organisation behaviour subscale was related to poor quality of written work.

\subsection{General ability subgroups}

Although participants in this study were selected solely on the basis of low scores on measures of working memory, their IQ scores were also low: the mean verbal IQ score of the sample was 72, and the mean performance IQ score was 85 (see Table 2). It was therefore important to establish the extent to which the patterns of problem behaviours characterizing this sample are characteristic of low cognitive abilities more generally, or of very poor working memory capacity in particular. For this purpose, children were assigned to two general ability categories on the basis of a composite WASI score calculated by averaging the $z$-scores within each age group for the raw scores on the verbal and performance tests. Children in the two age groups were then assigned either to the low or higher IQ group according to whether the $z$-scores were below or above .00 , respectively. In the younger group, 12 children were allocated to the low and 17 to the higher IQ groups; in the older group, the numbers were 12 and 11, respectively. For the younger children, the low ability subgroup had a mean raw verbal score of $6.00(\mathrm{SD}=.00)$, and a mean raw performance score of $3.00(\mathrm{SD}=1.41)$; for the higher ability subgroup, the mean raw scores were $13.80(\mathrm{SD}=3.49)$ and $4.00(\mathrm{SD}=2.45)$, respectively. In the older group, the low ability subgroup had a mean raw verbal score of $14.67(\mathrm{SD}=2.93)$, and a mean raw performance score of $5.33(\mathrm{SD}=1.50)$; for the higher ability subgroup, the mean raw scores were $13.80(\mathrm{SD}=3.49)$ and 4.00 $(\mathrm{SD}=2.45)$, respectively. 


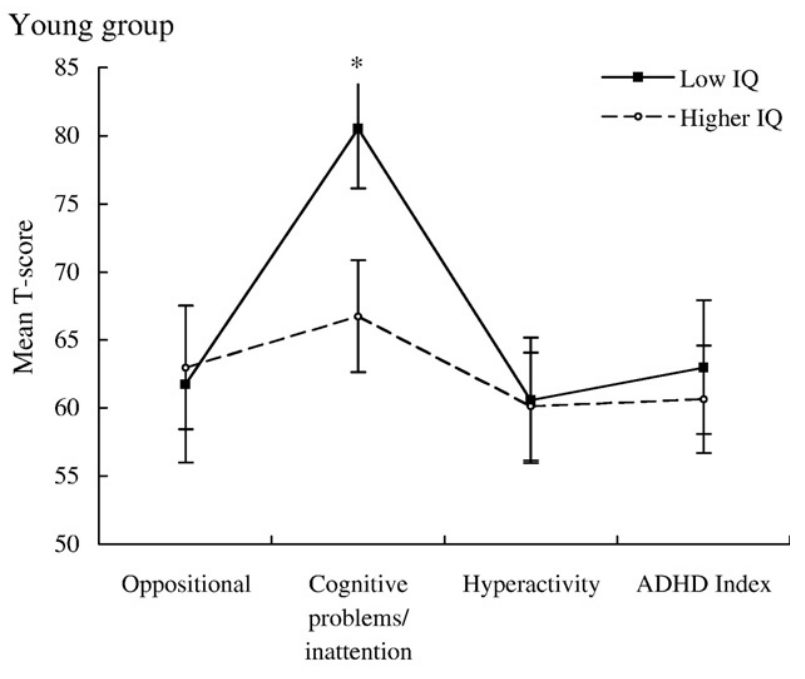

Older group

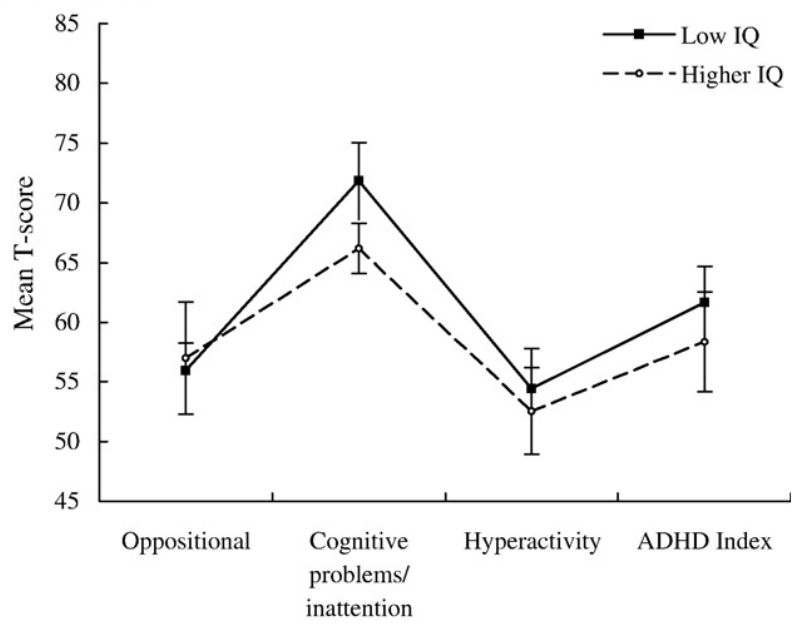

Fig. 1. Mean subscale scores (standard errors shown) on the Teacher Rating Scale for the low working memory groups, by IQ ability subgroups $\left({ }^{*} p<.05\right)$.

Mean subscale scores on the Conner's Teacher Rating Scale (2001) for the IQ subgroups of both the younger and older groups are shown in Fig. 1. Univariate $F$-tests were conducted for each subgroup comparison, and effect size $(d)$ scores were also calculated. Effect sizes of .20 are considered small, .50 medium, and .80 large in magnitude (Cohen, 1988). In the younger group, an IQ subgroup difference was found only on the cognitive problems/ inattention subscale, reflecting the higher (i.e., more problematic) scores of the low than the higher IQ subgroup $(p<.05, d=-.79)$. IQ subgroup differences on the other three subscales were nonsignificant $(p>.10)$ and effect sizes were very small, ranging from .07 to -.14 . No significant IQ subgroup differences were found in the older group ( $p>.10$ in each case), although scores on the cognitive problems/ inattention subscale were higher for the low IQ than the higher IQ subgroup, with a moderate effect size of -.59 . The remaining effect sizes were small, ranging from .09 to -.27 .

Corresponding descriptive statistics for the IQ subgroups at each age on the BRIEF measure are shown in Fig. 2. In the younger group, the subgroup factor was not significant on any of the univariate $F$-tests ( $p>.10$ in each case). Effect sizes were positive (reflecting fewer problem behaviours in the low than higher IQ subgroup) and/ or small in magnitude on each of the following subscales: inhibit (.13), shift (.48), emotional control $(.27)$, initiate $(.10)$, plan/ organize $((-.04)$ and monitor $(.13)$. However, two effects of moderate magnitude were found: working memory (-.31), and organization of materials (-.59).

Subgroup differences arising from elevated levels of problem behaviours in the low than the higher IQ subgroup were more marked in the older group, although significant effects of IQ subgroup were found only on the inhibit subscale $(p<.01, d=-1.04)$. Moderate effect sizes that reflected lower subscale scores of the higher IQ subgroup were found on the emotional control (-.78), shifting (-.71), working memory $(-.70)$ and organization of materials $(-.57)$ measures. The remaining effect sizes were: initiate $(-.08)$, plan/ organize $(.43)$, and monitor $(-.30)$. The lower levels of problem behaviours
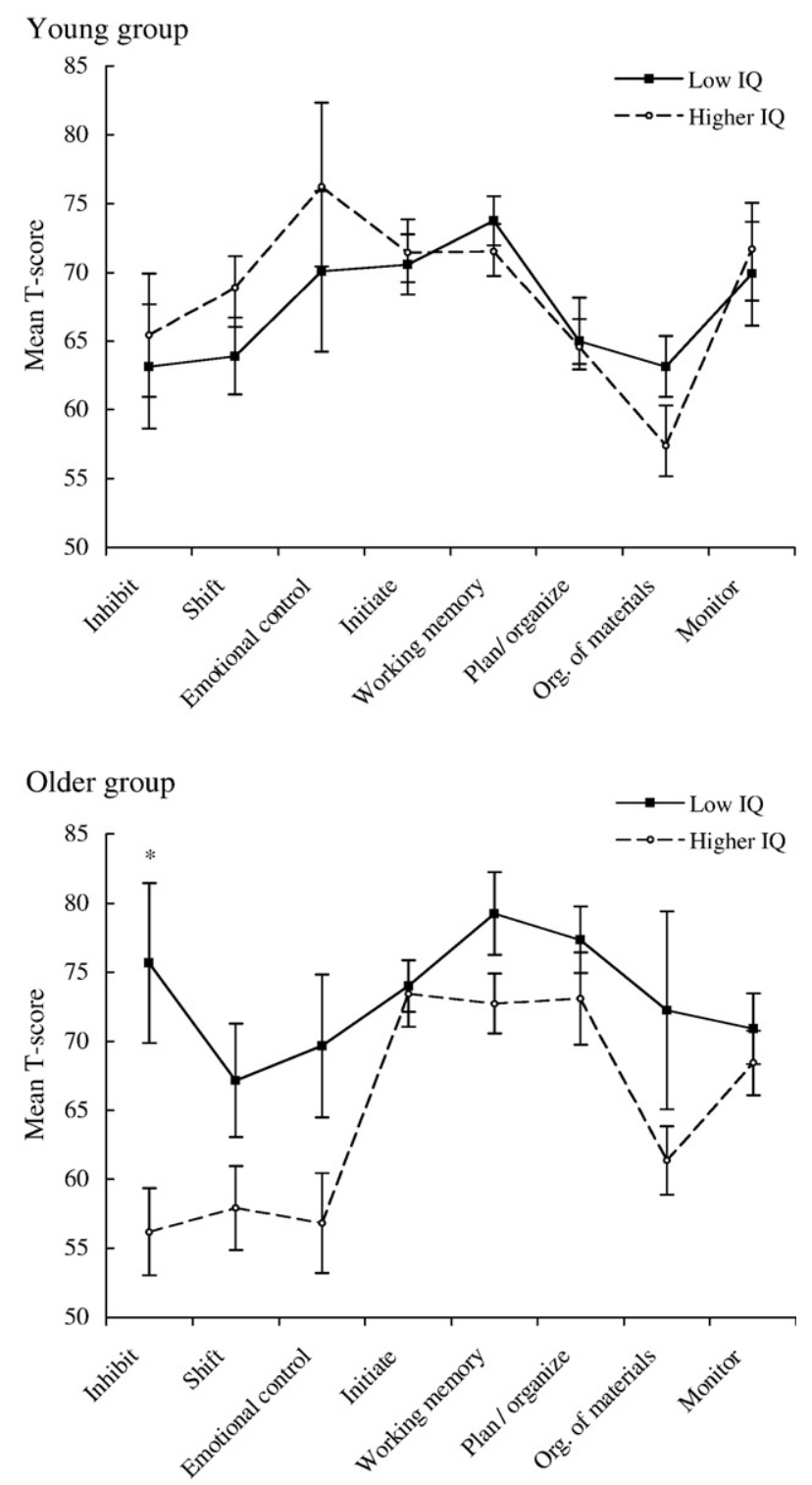

Fig. 2. Mean subscale scores (standard errors shown) on BRIEF measure of executive function behaviours for the low working memory groups, by IQ ability subgroups $\left({ }^{*} p<.01\right)$. 
relating to inhibition, shifting, emotional control, and the organization of materials in the higher ability subgroup resulting in mean scores on these subscales that fell considerably below 65 , the level considered to be of clinical significance (Gioia et al., 2000). In contrast, mean scores on the initiate, working memory, plan-organize and monitor subscales remained at clinically elevated levels even for the children with higher IQ scores.

\section{Discussion}

This study investigated the extent to which children aged 5/ 6 and $9 / 10$ years with poor verbal working memory were judged by teachers to exhibit classroom behaviours associated with problems of attention and executive function. The children's behaviour was found to be atypical in a number of respects. Consistent with their low levels of attainment in reading and mathematics, the majority of children of both ages were rated as having cognitive problems associated with poor academic progress, and also as having short attention spans and high levels of distractibility. The majority were also judged frequently to fail to monitor the quality of their work and to show a lack of creativity in solving complex problems. The frequency of oppositional and hyperactive behaviour was lower than those of cognitive problems and inattention, and was within the typical range for the older age group.

These results are consistent with the hypothesis that poor working memory function and inattentive behaviour are closely associated in non-clinical samples of children (see also, Aronen et al., 2005), extending recent findings from studies of children with ADHD diagnoses (Klingberg et al., 2005; Martinussen \& Tannock, 2006). They also fit well with evidence that typicallydeveloped adults with low working memory spans are more likely to experience mind wandering when they are engaged in demanding ongoing activities than individuals with higher working memory spans (Kane et al., 2007). We suggest that working memory problems and inattention might co-occur because the limited working memory capacity of such individuals is often inadequate to meet the storage and processing demands of everyday cognitive activities such as classroom learning activities (Gathercole \& Alloway, 2008; Gathercole et al., 2006). Working memory overload will lead to the loss from working memory of crucial task information, and this forgetting will compromise the child's chances of completing a task successfully, impeding the rate of learning and academic progress. A likely consequence of forgetting in the course of cognitively challenging activities is that the child will lose his or her focus on the task in hand, leading nongoal-directed behaviour that will appear to observers to be inattentive and distractible.

A second aim of the study was to explore whether the working memory deficits of these children extend to other executive functions, using the BRIEF behavioural measure of executive functions (Gioia et al., 2000). High rating of problems behaviours were obtained on the working memory, monitoring, inhibition, and planning/ organization subscales, and to a lesser extent on the remaining subscales of shifting and emotional control. The majority of children were judged to have poor attention spans and high levels of distractibility, failures to monitor the quality of their own work, and lack of creativity in solving problems. We have already suggested that the first area of problem, inattentive behaviour, may be a consequence of task forgetting due to working memory overload. The second problem, of monitoring of work, may also result from the loss from working memory of crucial task information; once lost, it cannot be used to check the work that has been completed and to make corrections where necessary. The third problem area, relating to difficulties in generating alternative solutions to complex problems, was not anticipated. It is, however, consistent with substantial evidence that working memory plays a key role in supporting reasoning (Kyllonen \& Chrystal, 1990; Oberauer, Weidenfield, \& Hornig, 2006), mathematical problem-solving (Swanson, 2006), and planning (Zook, Devalos, Delosh, \& Davis, 2004), and also with proposals that working memory may be involved in both the construction of mental models of problem solutions (JohnsonLaird \& Byrne, 1991) and the monitoring and manipulation of materials in the course of component mental calculations (Swanson, 2006). Perhaps the generation and evaluation of new solutions that differ from recently executed unsuccessful actions or approaches may impose storage burdens that exceed the low working memory capacities of these children. Of course, detailed issues regarding the direction of causality are inevitably raised by these associations. For example, executive function failures in areas such as attentional failures, task initiation, planning and monitoring of behaviour may be the cause rather than the consequence of the children's poor performance on the tests of working memory. While the present data are unable to resolve this issue, they do point to important areas for future research.

Although the frequency of some of these problem behaviours was associated with low general intellectual abilities in the sample, others were not. Cognitive problems related to poor learning were rated more highly in the low than higher IQ children in the young low working memory group; however, these problems remained at elevated levels even for the children of higher general abilities, and a significant difference between IQ subgroups was not found in the older group. In executive function behaviours, a significant difference between children with low and higher IQs was found only for the older group on the inhibit subscale. This is consistent with the previous evidence from individual differences studies that working memory and inhibitory control are distinct constructs in both children (St. Clair-Thompson \& Gathercole, 2006) and adults (Miyake et al., 2000). Problem behaviours relating to the initiation of activities, to working memory, to the planning and organization of behaviour, and to the monitoring of behaviour were maintained at sufficiently high levels to be considered to be of clinical significance in both low and higher ability subgroups, and therefore like cognitive problems relating to learning, do not seem to be readily attributable to a generalized decrement in cognitive efficiency indexed by IQ.

In summary, this study establishes that teachers view children with poor working memory as being inattentive, having short attention spans and high levels of distractibility. The majority of the children were also judged to exhibit behaviours associated with poor executive functioning, including poor monitoring of his or her own work, and also lack of 
creativity in solving complex problems. This profile of classroom behavioural problems may provide a window into why many children with poor working memory typically struggle to learn.

\section{Appendix A. Examples of items from BRIEF subscales}

\begin{tabular}{ll}
\hline $\begin{array}{l}\text { Inhibit } \\
\text { Gets out of control more } \\
\text { than friends }\end{array}$ & $\begin{array}{l}\text { Working memory } \\
\text { When given three things to do, } \\
\text { remembers only first or last }\end{array}$ \\
$\begin{array}{l}\text { Has trouble putting brakes } \\
\text { on his/ her actions }\end{array}$ & $\begin{array}{l}\text { Has a short } \\
\text { attention span }\end{array}$ \\
Shift & Plan/ organize \\
Acts upset by a change & Has good ideas but cannot get \\
of plans & them on paper \\
Thinks too much about & Becomes overwhelmed by \\
the same topic & large assignments \\
& Organization of materials \\
Emotional control & Cannot find things in room \\
Overreacts to small & or school desk \\
problems & Leaves a trail of belongings \\
Mood changes & wherever s/he goes \\
frequently &
\end{tabular}

\section{References}

Alloway, T. P. (2007). Automated working memory assessment. Harcourt Education. Alloway, T. P., Gathercole, S. E., \& Pickering, S. J. (2006). Verbal and visuo-spatial short-term and working memory in children: Are they separable? Child Development, 77, 1698-1716.

Anderson, V. A., Anderson, P., Northam, E., Jacobs, R., \& Mikiewicz, O. (2002). Relationships between cognitive and behavioral measures of executive function in children with brain disease. Child Neuropsychology, $8,231-240$.

Aronen, E. T., Vuontela, V., Steenari, M. -R., Salmi, J., \& Carlson, S. (2005). Working memory, psychiatric symptoms, and academic performance at school. Neurobiology of Learning and Memory, 83, 33-42.

Baddeley, A. D. (1986). Working memory. Oxford: Oxford University Press.

Baddeley, A. D. (2000). The episodic buffer: A new component of working memory? Trends in Cognitive Sciences, 4, 417-423.

Barkley, R. (1997). Behavioral inhibition, sustained attention, and executive function: Constructing a unified theory of ADHD. Psychological Bulletin, 121, 65-94.

Baddeley, A. D., \& Hitch, G. (1974). Working memory. In G. Bower (Ed.), The psychology of learning and motivation (pp. 47-90). New York: Academic Press.

Bayliss, D. M., Jarrold, C., Gunn, M. D., \& Baddeley, A. D. (2003). The complexities of complex span: Explaining individual differences in working memory in children and adults. Journal of Experimental Psychology: General, 132, 71-92.

Catellanos, F. X., Sonuga-Barke, E. J. S., Milham, M. P., \& Tannock, R. (2006). Characterizing cognition in ADHD: Beyond executive dysfunction. Trends in Cognitive Sciences, 10, 117-123.

Cohen, J. (1988). Statistical power analysis for the behavioural sciences, (2nd ed.). Hillsdale, NJ: Lawrence Erlbaum Associates.

Conners, C. K. (2001). Conners Rating Scale—Revised. North Tunawanda, NY: Multihealth Systems.
Dunn, L. M., Dunn, L. M., Whetton, C. W., \& Pintillie, D. (1997). The British Picture Vocabulary Scales-Revised. Windsor, UK: NFER Nelson.

Engle, R. W., Carullo, J. J., \& Collins, K. W. (1991). Individual differences in working memory for comprehension and following directions. Journal of Educational Research, 84, 253-262.

Gathercole, S. E., \& Alloway, T. P. (2008). Working memory and learning: A guide for teachers. Sage: UK.

Gathercole, S. E., Alloway, T. P., Willis, C. S., \& Adams, A. M. (2006). Working memory in children with reading disabilities. Journal of Experimental Child Psychology, 93, 265-281.

Gathercole, S. E., Lamont, E., \& Alloway, T. P. (2006). Working memory in the classroom. In S. Pickering \& G. Phye (Eds.), Working memory and education (pp. 219-240). US: Academic Press.

Gathercole, S. E., Pickering, S. J., Knight, C., \& Stegmann, Z. (2004). Working memory skills and educational attainment: Evidence from national curriculum assessments at 7 and 14 years of age. Applied Cognitive Psychology, 18, 1-16.

Geary, D. C., Hoard, M. K., Byrd-Craven, J., \& DeSoto, M. C. (2004). Strategy choices in simple and complex addition: Contributions of working memory and counting knowledge for children with mathematical disability. Journal of Experimental Child Psychology, 88, 121-151.

Gioia, G. A., Isquith, P. K., Guy, S. C., \& Kenworthy, L. (2000). Behavior rating inventory of executive function. Florida, USA: Psychological Assessment Resources, Inc.

Johnson-Laird, P. N., \& Byrne, R. M. J. (1991). Deduction. Hove, UK: Lawrence Erlbaum Associates Ltd.

Kane, M. J., Brown, L. H., Little, J. C., Silvia, P. J., Myin-Germeys, I., \& Kwapil, T. R (2007). For whom the mind wanders and when: An experience-sampling study of working memory and executive control in daily life. Psychological Science, $18,614-621$.

Kane, M. J., Hambrick, D. Z., Tuholski, S. W., Wilhelm, O., Payne, T. W., \& Engle, R. W. (2004). The generality of working-memory capacity: A latentvariable approach to verbal and visuo-spatial memory span and reasoning. Journal of Experimental Psychology: General, 133, 189-217.

Klingberg, T., Fernell, E., Olsesen, P. J., Johnson, M., Gustafsson, P., Dahlstrom, K., et al. (2005). Computerized training of working memory in children with ADHD-A randomized, controlled trial. Journal of the American Academy of Child and Adolescent Psychiatry, 44, 177-186.

Kyllonen, P. C., \& Chrystal, R. E. (1990). Reasoning ability is (little more than) working memory capacity. Intelligence, 14, 389-433.

Mahone, E. M., Zabel, T. A., Levey, E., Verda, M., \& Kinsman, S. (2002). Paren and self-report ratings of executive function in adolescents with myelomeningocele and hydrocephalus. Child Neuropsychology, 8, 258-270.

Martinussen, R., \& Tannock, R. (2006). Working memory impairments in children with ADD with and without comorbid language learning disorders. Journal of Clinical and Experimental Neuropsychology, 28, 1073-1094.

Martinussen, R., Hayden, J., Hogg-Johnson, S., \& Tannock, R. (2005). A metaanalysis of working memory impairments in children with attention-deficit/ hyperactivity disorder. Journal of American Academy of Child and Adolescent Psychiatry, 44, 377-384.

Mehta, M. A., Goodyer, I. M., \& Sahakian, B. J. (2004). Methylphenidate improves working memory and set-shifting in $\mathrm{AD} / \mathrm{HD}$ : Relationships to baseline memory capacity. Journal of Child Psychology and Psychiatry, 45, 293-305

Miyake, A., Friedman, N. P., Emerson, M. J., Witzki, A. H., Howerter, A., \& Wager, T. D. (2000). The unity and diversity of executive functions and their contributions to complex 'frontal lobe' tasks: A latent variable analysis. Cognitive Psychology, 41, 49-100.

Nigg, J. T. (2001). Is ADHD a disinhibitory disorder? Psychological Bulletin, 127, 571-598.

Oberauer, K., Weidenfeld, A., \& Hornig, R. (2006). Working memory capacity and the construction of spatial mental models in comprehension and deductive reasoning. Quarterly Journal of Experimental Psychology, 59, 426-447.

Pennington, B. F., \& Ozonoff, S. (1996). Executive functions and developmental psychopathology. Journal of Child Psychology and Psychiatry and Allied Disciplines, 37(1), 51-87.

Pickering, S. J., \& Gathercole, S. E. (2004). Distinctive working memory profiles in children with special educational needs. Educational Psychology, 24, 393-408 
St Clair-Thompson, H. L., \& Gathercole, S. E. (2006). Executive functions and achievements on national curriculum tests: Shifting, updating, inhibition, and working memory. Quarterly Journal of Experimental Psychology, 59, 746-759.

Slick, D. J., Lautzenhiser, A., Sherman, E. M. S., \& Eyrl, K. (2006). Frequency of scale elevations and factor structure of the Behavior Rating Inventory of Executive Function (BRIEF) in children and adolescents with intractable epilepsy. Child Neuropsychology, 12, 181-189.

Stuss, D. T., \& Alexander, M. P. (2005). Does damage to the frontal lobes produce impairment in memory? Current Directions in Psychological Science, 14, 84-88.

Swanson, H. L. (2006). Cross-sectional and incremental changes in working memory and mathematical problem solving. Journal of Educational Psychology, 98, 265-281.

Swanson, H. L., Ashbaker, M. H., \& Lee, C. (1996). Learning disabled readers working memory as a function of processing demands. Journal of Experimental Child Psychology, 61, 242-275.

Thompson, J. M., Hamilton, C. J., Gray, J. M., Quinn, J. G., Mackin, P., Young, A. H., \& Ferrier, I. N. (2006). Executive and visuospatial sketchpad resources in euthymic bipolar disorder: Implications for visuospatial working memory architecture. Memory, 14, 437-451.

Tripp, G., Schaughency, E. A., \& Clarke, B. (2006). Parent and teacher rating scales in the evaluation of attention-deficit hyperactivity disorder: Contribution to diagnosis and differential diagnosis in clinically referred children. Journal of Developmental and Behavioural Pediatrics, 27, 209-218.

Wechsler, D. (1999). Wechsler abbreviated scale of intelligence. London: Psychological Corporation.

Wechsler, D. (1993). Wechsler objective reading dimensions. London: Psychological Corporation.

Wechsler, D. (1996). Wechsler objective numerical dimensions. London: The Psychological Corporation .

Willcutt, E. G., Doyle, A. E., Nigg, J. T., Faraone, S. V., \& Pennington, B. F. (2005). Validity of the executive function theory of attention-deficit/ hyperactivity disorder: A meta-analytic review. Biological Psychiatry, 57, 1336-1346.

Zook, N. A., Davalos, D. B., DeLosh, E. L., \& Davis, H. P. (2004). Working memory, inhibition, and fluid intelligence as predictors of performance on Tower of Hanoi and London tasks. Brain and Cognition, 56, 286-292. 